\title{
Road Sign Detection Distance and Reading Distance at an Uncontrolled Intersection
}

\author{
Mohamad Ihsan Priambodo ${ }^{1}$ and Martha Leni Siregar ${ }^{1 *}$ \\ ${ }^{1}$ Department of Civil Engineering, Faculty of Engineering, Universitas Indonesia, Kampus Baru UI \\ Depok, 1624 Depok, Jawa Barat, Indonesia
}

\begin{abstract}
A traffic sign needs to be located at a distance that allows drivers to read and understand the message prior to their decision in manoeuvring. The study is aimed at evaluating signs visibility at intersections without traffic lights using the drivers reading distance and detection distance. A total of 35 participants with valid driver's licences were asked to detect and read 6 advance guide signs at an intersection without traffic lights on an urban road. Factors that potentially determine signs readability and visibility such as vehicle's speed, vehicle's travelling time, signs vertical offset and signs letter height which affect signs detection distance and reading distance are analyzed using multivariate regression. The experiment was conducted during night time to present heavier driving and sign reading environment. The positions of the signs were evaluated based on the actual sign positions and the detection and reading distances. Some of the findings include that vehicle travel time, vehicle speed, sign letter height, and sign vertical offset all significantly have a relationship with the sign reading distance whilst sign letter height does not have a significant relationship with the detection distance. The study also evaluated the signs compliance with the applied standards.
\end{abstract}

\section{Introduction}

A traffic accident caused by the less aware driver, most commonly occur at low-volume urban roads with fewer control tools to notify the drivers of the environment or obstacle ahead. Traffic signs as one of the control tools on the roads need to be positioned properly to lower accidents risks. Traffic signs need to be visible and readable to drivers to serve the safety function especially at night times [1]. When reviewing the sign visibility, many studies often divide it into two main areas: sign detection and sign reading [1-4]. These areas are interdependent as drivers cannot read a sign whose presence cannot be detected and cannot understand the message delivered in a sign if it is not readable from the driving position [5].

There have been studies on the visibility of signs by various drivers' characteristics such as age and gender and by types of retro-reflective sheeting materials performance [1-4]. However, studies on the visibility of signs in regards to the positions still need to be explored. Sign detectability and visibility are crucial in traffic safety and are part of a self-

\footnotetext{
* Corresponding author: leni@eng.ui.ac.id
} 
explaining road system [6]. The study was carried out to determine traffic signs visibility which is characterized by traffic sign detectability and legibility. Indonesia applies the standard of traffic signs based on the Ministry of Transportation Law No.13 of 2014 on Traffic Signs [7]. The law regulates the installation and position of traffic signs but does not set the minimum detection and reading distance. Therefore, this study measures the detection and reading distance of the traffic signs in reference to Traffic Sign Manual (TSM) [8] from United Kingdom (UK) and Manual on Traffic Control Devices (MUTCD) in Federal Highway Administration year 2009 (FHWA 2009) from United States of America (USA) [5]. In TSM, reading distance is taken from the cut-off distance and the minimum reading distance of traffic sign cut-off distance is defined as the distance where a driver is supposedly stopped reading the sign [8], it was taken from the equation below:

$$
C=S \times 1 / \sin \left(8^{\circ}\right)=S \times 7.2
$$

Where $C$ is cut-off distance, $S$ is a vertical offset of a traffic sign, and angle $8^{\circ}$ is the minimum angle of the vertical axis of the sign where the sign should fell [5].

Detection distance is taken from a reading distance plus cut-off distance. It is desirable to provide a proper detection distance that is equal to or greater than that signs reading distance [5]. The reading distance is taken from the equation below:

$$
R=\text { reading time } \mathrm{x} \text { vehicle's speed }
$$

Where $R$ is reading distance, the vehicle speed is the speed of the vehicle when reading or detecting a sign and reading time is obtained from the maximum time to read an advance guide sign, 4 seconds taken from TSM [8].

In MUTCD (FHWA 2009), distance legibility is taken from legibility index (LI) of 30 feet per inch of letter height $(\mathrm{LI}=30)$. Legibility index means that a sign with 10 -inch letters legible at 300 feet has an LI of $30 \mathrm{ft} / \mathrm{in}(300 / 10=30)$ [2, 5]. In this study, LI 30 is used to determine the minimum reading distance of traffic sign by using its actual letter height multiplied by 30 . Multivariate regression analysis was utilized in this study to find the influencing variables on the detection and reading distances and the correlations.

\section{Research methodology}

The survey was performed on an urban road during night time using controlled road studies. Thirty-five participants were recruited to participate in the experiment and participants with vision problems were reminded to wear corrective lens or glasses. Factors such as gender and age were ignored in this experiment. The participants were individually asked to drive the vehicle while an experimenter sat in the passenger seat [9]. Data recorded included participant's detection distance and reading distance of 6 advance guide signs, as well as vehicle speed and travel time. Smartphone application My Track, which uses Global Positioning System (GPS), was used in the data collection as in Figure 2. The application recorded the route taken along with time, speed, altitude, duration and distances. The signs studied in this research was advance guide signs in accordance with the Ministry of Transportation Law No.13 of 2014 on Traffic Signs.

The experiment was performed during clear night time (clear weather, no rainy or cloudy night) to heavier driving and sign reading environment. The vehicle used for the experiment was a 2008 Honda Jazz passenger car. Also, to help process the data, a dashboard camera with timestamp was mounted facing towards the participants as shown in Figure 2. Clear instructions were briefed to the participants to avoid unnecessary errors and mistakes during the reading. The procedures taken were as follow: 


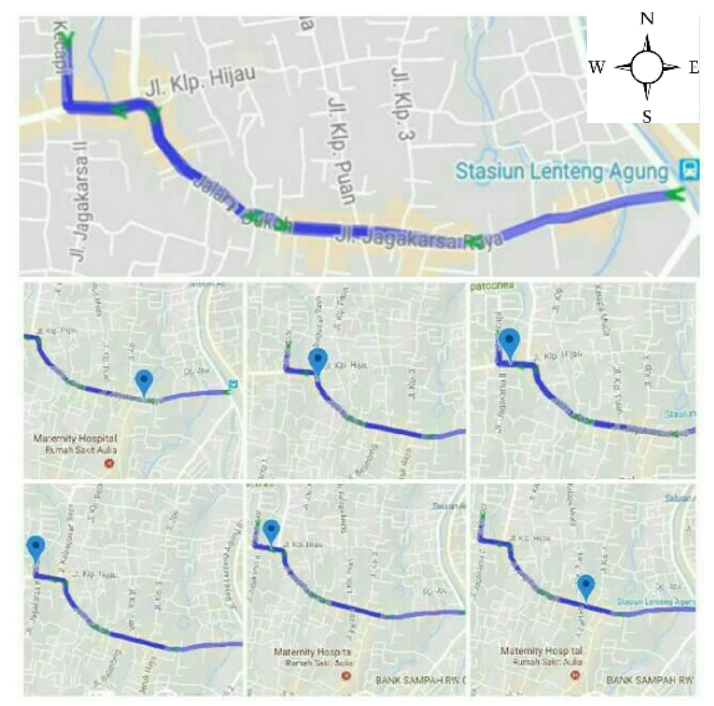

Fig. 1. Experimental route on Jagakarsa Raya, South Jakarta

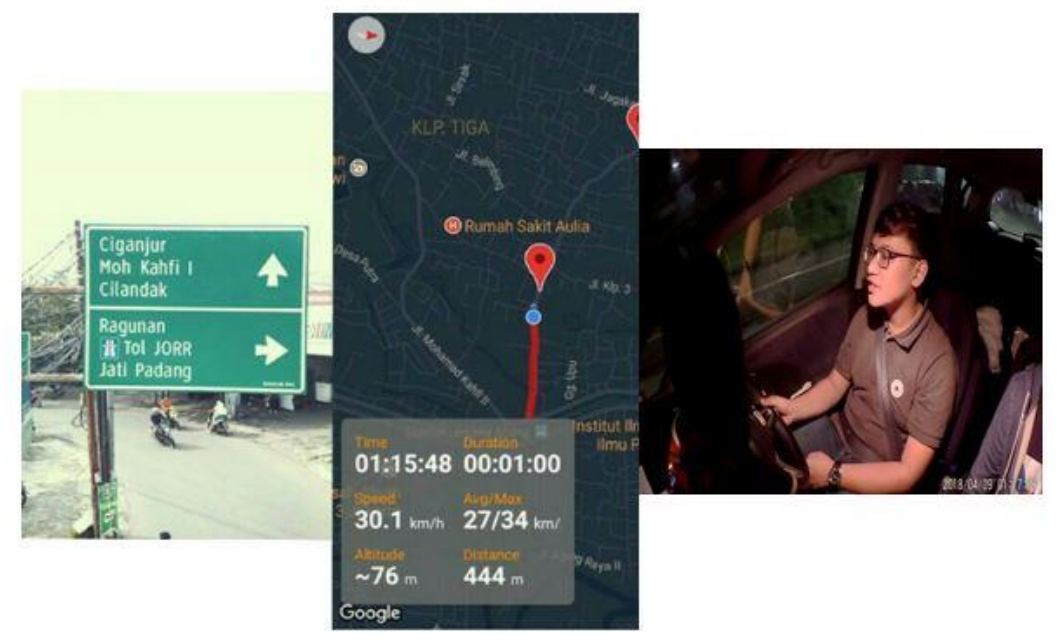

Fig. 2. A typical advance guide sign, My Track application display, and participant performing the experiment

- Participants were seated in the driver's seat while experimenter is seated in the passenger's seat,

- The participants were asked to read only advance guide signs along on the designated route and participants were made aware of the advance guide signs around 500 metres before the location of the signs.

- The participants were asked to notify the experimenter when the participants detect and read the signs by saying "can detect" if they can detect the sign, "can read" if they can read the sign, and "can do both" if they can detect and read the sign simultaneously.

- This procedure was repeated for a total of six advance guide signs along Jagakarsa Raya roads. 
Sign vertical offset and sign letter height as a sign placement and sign variable that affect sign's detection and reading distance were obtained using a laser gauge.

\section{Results and discussion}

\subsection{Sign reading distance and detection distance characteristics}

From the experimental driving, it was obtained that, sign 6 has the maximum sign detection distance which is 160 metres and has the longest average detection distance which is 104.86 metres. Sign 1 has the same maximum sign reading distance with sign number 6 , which is 100 metres. But, sign 1 average reading distance is 54.86 metres which are longer than sign 6. Sign 6 has the longest average and maximum detection distance. The reading also indicates that the low-grade retro-reflective sheeting material of sign 6 caused it to have low visibility, whilst it has been shown that the visibility of sign at night depends on its retro-reflectivity [1].

The mean values of signs 1, 4 and 6 are comparatively higher than those of signs 2, 3, and 5 . The field survey indicated that the difference could be the result of road geometry which provides poor sight distance for drivers to detect the signs earlier.

Table 1. Sign reading distance $(\mathrm{m})$

\begin{tabular}{|c|c|c|c|}
\hline Sign & Minimum & Maximum & Mean \\
\hline 1 & 40 & 100 & 69.14 \\
\hline 2 & 10 & 40 & 28.27 \\
\hline 3 & 10 & 40 & 24.57 \\
\hline 4 & 30 & 90 & 58 \\
\hline 5 & 20 & 50 & 32.57 \\
\hline 6 & 20 & 100 & 54.86 \\
\hline
\end{tabular}

Table 2. Sign detection distance $(\mathrm{m})$

\begin{tabular}{|c|c|c|c|}
\hline Sign & Minimum & Maximum & Mean \\
\hline 1 & 60 & 120 & 97.14 \\
\hline 2 & 20 & 60 & 42 \\
\hline 3 & 20 & 50 & 30.57 \\
\hline 4 & 60 & 130 & 98.27 \\
\hline 5 & 20 & 60 & 43.14 \\
\hline 6 & 40 & 160 & 104.86 \\
\hline
\end{tabular}

\subsection{Comparison of sign detection and reading distance with TSM and MUTCD (FHWA 2009)}

Comparing the sign detection and reading distance from the experimental driving with detection distance and reading distance according to TSM, it was shown that signs number 1,4 , and 6 reading distances exceeded the cut-off distance while signs number 2, 3 and 5 did not. The sign detection distances of signs 1,4 and 6 also exceeded the reading distance plus cut-off distance. 
Table 3. Sign reading distance and cut-off distance (TSM)

\begin{tabular}{rrrrrr}
\hline Sign & $\begin{array}{c}\text { Vertical } \\
\text { Offset }(\mathrm{m})\end{array}$ & $\begin{array}{c}\text { Cut-Off } \\
\text { Distance }(\mathrm{m})\end{array}$ & $\begin{array}{c}85 \\
\text { percentiles } \\
(\mathrm{km} / \mathrm{h})\end{array}$ & $\begin{array}{c}\text { Reading } \\
\text { Distance }(\mathrm{m})\end{array}$ & $\begin{array}{c}\text { Reading Distance }+ \\
\text { Cut-Off Distance } \\
(\mathrm{m})\end{array}$ \\
\hline 1 & 6.22 & 45 & 25.59 & 28 & 73 \\
\hline 2 & 5.06 & 36 & 20.23 & 22 & 59 \\
\hline 3 & 5.01 & 36 & 22.09 & 25 & 61 \\
\hline 4 & 5.18 & 37 & 30.70 & 34 & 71 \\
\hline 5 & 4.72 & 34 & 22.37 & 25 & 59 \\
\hline 6 & 5.51 & 40 & 26.35 & 29 & 69 \\
\hline
\end{tabular}

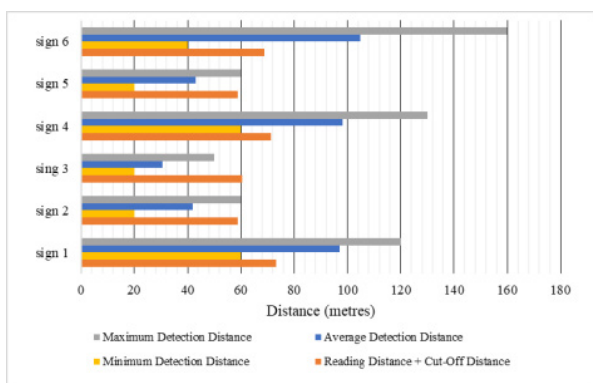

Fig. 3.1 Comparison of sign detection distance with TSM

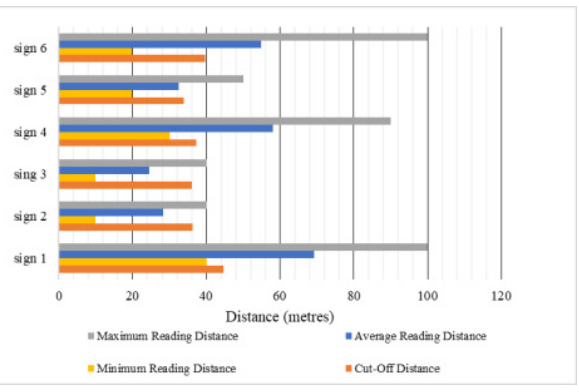

Fig. 3.2 Comparison of sign reading distance with TSM

Based on MUTCD (FHWA 2009), it is indicated that only sign 4 has reading distance exceeding the LI 30 which might be due to the smaller letter height used in sign 4 . However, when the minimum letter height was in accordance with the Indonesian law [7], the minimum reading distance was measured 54 metres. Therefore, signs 1,4 and 6 reading distances are found to exceed the $54 \mathrm{~m}$ reading distance.

Table 4. Sign Legibility Index

\begin{tabular}{crr}
\hline Sign & Letter Height $(\mathrm{mm})$ & Legibility Index $30(\mathrm{~m})$ \\
\hline 1 & 237.74 & 86 \\
\hline 2 & 181.69 & 65 \\
\hline 3 & 218.46 & 79 \\
\hline 4 & 158.66 & 57 \\
\hline 5 & 186.18 & 67 \\
\hline 6 & 254.04 & 91 \\
\hline
\end{tabular}




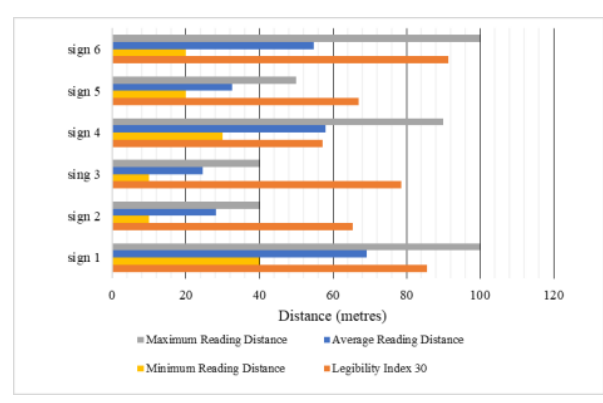

Fig. 4.1 Comparison of reading distances with MUTCD (FHWA 2009)

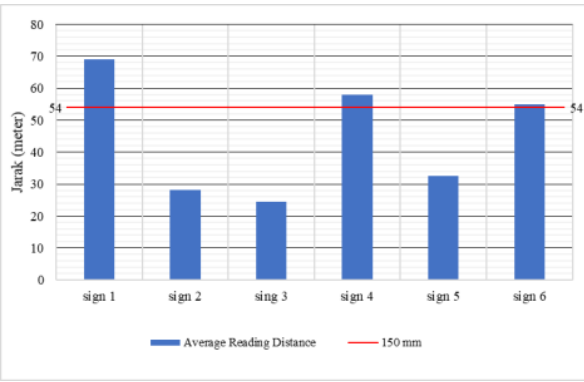

Fig. 4.2 Comparison of reading distances with MUTCD (FHWA 2009) using minimum letter height $150 \mathrm{~mm}$

The reading of signs 2, 3, and 5 do not exceed the distances set in MUTCD (FHWA 2009) when using minimum letter height 150 millimetres according to Indonesia's Ministry of Transportation regulation and TSM criteria. The possibility might be due to the geometry of the road which does not provide adequate sight distances for drivers to detect and read the sign from the minimum distance according to MUTCD (FHWA 2009) and TSM criteria. The vertical offsets of signs 1, 4 and 6 are greater than the other three signs.

\subsection{Variables correlations to sign detection distance and reading distance}

Vehicle speed, sign vertical offset, sign letter height, and vehicle travel time was statistically analysed. The speed measured is the operating speed which is the 85 percentiles of vehicles speeds which is also referred to as desirable operating speed [7, 10]. The analysis was performed using multivariate regression to check the correlations between variables and sign detection distance and reading distance and to check the effect of its individual variables to sign detection distance and reading distance. Analysis using multivariate regression were conducted using IBM SPSS Statistics version 25. The Pearson's Correlation and t-test of the regression are shown in Tables 5 and 6.

Table 5. Pearson's Correlation

\begin{tabular}{lcccc}
\hline \multicolumn{1}{c}{$\begin{array}{c}\text { Pearson } \\
\text { Correlation }\end{array}$} & $\begin{array}{c}\text { Sign Reading } \\
\text { Distance }\end{array}$ & Sig. & $\begin{array}{c}\text { Sign Detection } \\
\text { Distance }\end{array}$ & Sig. \\
\hline $\begin{array}{l}\text { Vehicle } \\
\text { travel time }\end{array}$ & 0.297 & 0.000 & 0.378 & 0.000 \\
\hline $\begin{array}{l}\text { Vehicle } \\
\text { speed }\end{array}$ & 0.291 & 0.000 & 0.401 & 0.000 \\
\hline $\begin{array}{l}\text { Sign } \\
\text { letter height }\end{array}$ & 0.237 & 0.000 & 0.207 & 0.000 \\
\hline $\begin{array}{l}\text { Sign } \\
\text { vertical off-set }\end{array}$ & 0.643 & 0.000 & 0.613 & 0.000 \\
\hline
\end{tabular}

Using the $90 \%$ Confidence Interval, it can be shown that the variables are significant (sig. $<0.05)$ and correlate in the same direction assign reading distance and detection distance. The highest correlation is found to be between signs vertical off-set and sign reading distance. Sign vertical off-set was also the variable which has the highest correlation with sign detection distance. 
Table 6. T-Test

\begin{tabular}{lcccccc}
\hline \multirow{2}{*}{ C } & \multicolumn{2}{c}{ Sign Detection Distance } & \multicolumn{3}{c}{ Sign Reading Distance } \\
\cline { 2 - 7 } & $\mathrm{B}$ & $\mathrm{t}$ & $\mathrm{Sig}$. & $\mathrm{B}$ & $\mathrm{t}$ & Sig. \\
\hline (Constant) & -174.524 & -10.364 & 0.000 & -114.419 & -10.375 & 0.000 \\
\hline Vehicle's travel time & 1.657 & 9.656 & 0.000 & 1.104 & 6.846 & 0.000 \\
\hline Vehicle speed & 2.675 & 9.255 & 0.000 & 1.025 & 5.400 & 0.000 \\
\hline Sign letter height & -0.036 & -0.599 & 0.550 & -0.089 & -2.226 & 0.027 \\
\hline Sign vertical off-set & 33.398 & 7.610 & 0.000 & 27.851 & 9.627 & 0.000 \\
\hline
\end{tabular}

The tables contain regression coefficients, standard errors, t-statistics and probability values. The regression coefficients indicate how much sign detection distance and reading distance increase with unit increases in independent variables. The t-statistics and probability values show how statistically significant independent variables are as predictors of detection and reading distances. From Table 6 independent variables vehicle travel time, vehicle speed and sign vertical off-set are directly related to both sign detection distance and sign reading distance in a positive relationship and are significant at the 0.001 level or beyond. Independent variable sign letter height is not related to signing detection distance but has a less significant and inverse relationship to reading distance. This finding is quite unexpected as it indicates that with bigger letter heights, drivers need to get closer to the position of the sign to read the signs. As the survey was conducted at night time, the legibility of the signs may also be influenced the letter retro-reflective sheeting materials performance.

\section{Conclusions}

The evaluation of sign reading distance and detection distance results in only one sign on the study area that fulfils all the standard, two signs are sub-standardized to the MUTCD (FHWA 2009) standard using LI 30. The rest 3 signs are sub-standardized to all referred standards, a probability being the inadequate provision of sight distance of the road sections. In addition, some signs are partially obstructed which causes shorter detecting and reading distances. Further analysis using multivariate regression, shows that in sign reading distance: vehicle travel time, vehicle speed, sign letter height, and sign vertical offset all significantly affect the sign reading distance whilst sign letter height does not significantly influence the detection distance.

This research was supported by Universitas Indonesia PITTA (Publikasi Internasional Untuk Tugas Akhir Mahasiswa UI) Grant, 2018 contract number: 2475/UN2.R3.1/HKP.05.00/2018.

\section{References}

1. Mohamed Said Obeidat, Malgorzata J. Rys, Andrew Rys, Juan Du. Elsevier. Applied Ergonomics. 56. (2016)

2. Dillon Funkhouser, Susan Chrysler, Alicia Nelson, Eun Sug Park. Traffic Sign Legibility for Different Sign Background Colors: Results of an Open Road Study at Freeway Speeds. Proceedings of the Human Factors and Ergonomics Society. 52. (2008) 
3. Paul J. Carlson. Can Traffic Signs Be Too Bright on Low Volume Roads? Eldon J. Yoder Outstanding Paper Award. (2015)

4. Yukiharu Akagi, Takuya Seo, Yoshitaka Motoda. Influence of the Visual Environment on Visibility of Traffic Signs. Transportation Research Record. (1996)

5. Philip M. Garvey, Beverly T. Kuhn. Handbook of Transportation Engineering. 2. Part III page 7.1-7.17 (2011)

6. Indonesia's Ministry of Transportation. Ministry of Transportation Regulation No.13 of 2014 on Traffic Signs (2014)

7. Tom V. Mathew, K. V. Krishna Rao, Introduction to Transportation Engineering (2007)

8. Department of Transport Northern Ireland. Traffic Signs Manual. (2004)

9. Marc Green. "How Long Does It Take to Stop?" Methodological Analysis of Driver Perception-Brake Times. Transportation Human Factors. 2. 195-216. (2000)

10. Cindy Irene Kawulur, T. K. Sendow, E. Lintong, A. L. E. Rumayar. Analisa Kecepatan yang Diinginkan Oleh Pengemudi (Studi Kasus Ruas Jalan Manado-Bitung). Jurnal Sipil Statik. 1. 289-297. (2013) 